\title{
Adsorption of Mercury (II) from Liquid Solutions Using Modified Activated Carbons
}

\author{
Hugo Soé Silva*, Silvia Virginia Ruiz, Dolly Lucía Granados, Juan Manuel Santángelo \\ Departamento de Ingeniería Química, Facultad de Ingeniería, \\ Universidad Nacional de San Juan, \\ Av. Libertador Gral. San Martín 1109 (oeste), 5400, San Juan, Argentina
}

Received: June 5, 2009; Revised: March 2, 2010

\begin{abstract}
Mercury is one of the most toxic metals present in the environment. Adsorption has been proposed among the technologies for mercury abatement. Activated carbons are universal adsorbents which have been found to be a very effective alternative for mercury removal from water. The effectiveness with which a contaminant is adsorbed by the solid surface depends, among other factors, on the charge of the chemical species in which the contaminant is in solution and on the net charge of the adsorbent surface which depend on the $\mathrm{pH}$ of the adsorption system. In this work, activated carbon from carbonized eucalyptus wood was used as adsorbent. Two sulphurization treatments by impregnation with sulphuric acid and with carbon disulphide, have been carried out to improve the adsorption capacity for mercury entrapment. Batch adsorption tests at different temperatures and $\mathrm{pH}$ of the solution were carried out. The influence of the textural properties, surface chemistry and operation conditions on the adsorption capacity, is discussed.
\end{abstract}

Keywords: mercury, aqueous solution, adsorption, activated carbon

\section{Introduction}

Mercury is an important and useful industrial material. Mercury and mercury compounds have been used from a long time as pigments in inks (cinnabar, red sulphide), as aids to early metallurgy (gilding copper) and instrumentation (thermometers, barometers) and in many industries (recovery of gold from its ores, manufacture of chlorine and sodium hydroxide by electrolysis of brine, etc.), or are present in their wastewaters.

Mercury is one of the most toxic metals present in the environment. Once mercury enters the food chain, large concentrations of this element accumulate in humans and animals, causing numerous adverse effects on their health. In order to prevent the problems due to the toxicity of mercury, several technologies have been proposed to remove this metal from aqueous media, which include ion exchange, adsorption, sulphide precipitation, electrodeposition, solvent extraction and membrane processes ${ }^{1}$. Among the available technological alternatives for the removal of trace metals from water, adsorption has been considered an economically feasible one ${ }^{2-8}$.

Activated carbons are universal adsorbents that can be obtained from a wide variety of raw materials including wastes of industrial activities $^{9-13}$. Activated carbons have been found to be a very effective alternative for mercury removal from water ${ }^{14-21}$.

Adsorption in liquid phase is a complex phenomenon because both, solute and solvent, compete for the solid surface. Briefly, the adsorption of a solute depends on its molecular size and chemical properties, on the textural properties of the adsorbent and on its surface chemistry ${ }^{22-23}$.

Most of the mercury in solution exists as complexed species, which can be either positive, negative or neutral, depending on the composition and $\mathrm{pH}$ of the solution. The situation is further complicated because the type of species preferentially adsorbed and the extent of adsorption may depend on the state of ionization of the surface which, in turn, is dependent on the solution $\mathrm{pH}^{24}$.

If the $\mathrm{pH}$ of an effluent cannot be modified (for example, when great volumes of liquid have to be decontamined or when this modification produces an environmental problem), the capture of a contaminant can be enhanced by surface modification of the adsorbent by means of suitable treatments ${ }^{25-29}$. In other cases it is possible to change the $\mathrm{pH}$ of the solution in order to improve the adsorption.

In the past few years, considerable attention has been devoted to develop surface-modified adsorbents in order to enhance the adsorption capacity of solids to eliminate mercury from aqueous media. Sulphur has been reported as an element which favours the adsorption of mercury ${ }^{30-35}$, therefore, the surface treatment which incorporates sulphur should improve the entrapment of species that contain mercury.

This contribution presents a comparative study of three activated carbons obtained from eucalyptus wood, as adsorbents of mercury in liquid phase. The first adsorbent was obtained by physical activation of carbonized eucalyptus wood with water vapour, following the protocol detailed in previous works ${ }^{36-37}$. Two samples of this activated carbon were separated and treated with sulphuric acid and with carbon disulphide, respectively, in order to introduce sulphur as a heteroatom onto the adsorbent surface.

Batch adsorption assays to entrap mercury were performed for all the activated carbons and the adsorption isotherms were used to compare their performance.

The structural and textural parameters of the adsorbents, as well as the operation variables (temperature and $\mathrm{pH}$ ) were analized and their influence on the adsorption capacity of the solids was discussed. 


\section{Experimental}

\subsection{Preparation of adsorbents}

The adsorbents were obtained from eucalyptus wood (EW). The start material was carbonized in a $5 \mathrm{~L}$ stainless steel retort, electrically heated, in absence of air from room temperature to $773 \mathrm{~K}$ and kept at the final temperature for 2 hours.

The carbonized material (CEW) was placed as a fixed bed in a $30 \mathrm{~mm}$ internal diameter stainless steel reactor, electrically heated, and activated with water vapour, following the protocol detailed in previous woks ${ }^{36-37}$. Basically, the reactor was heated from room temperture to the activation temperature $(1153 \mathrm{~K})$ under nitrogen atmosphere. Then, the nitrogen stream was replaced by a water vapour flow (1.7 $\mathrm{g}$ of steam per $\mathrm{g}$ of carbonized material and per hour). An activation time of 105 minutes was adopted. When the activation process finished, the whole system was cooled from $1153 \mathrm{~K}$ to room temperature under nitrogen flow. The activation yield was $47,3 \%$, measured as (mass of activated carbon/ mass of carbonized eucalyptus wood) $\times 100$.

Two fractions of activated material (AC) were used to carry out the surface treatments of the adsorbent in order to incorporate sulphur as heteroatom onto the carbon surface. In one of the surface treatments, $50 \mathrm{~g}$ of AC were soaked in $250 \mathrm{~mL}$ of concentrated sulphuric acid, at room temperature, under stirring, for 24 hours. The liquid fraction was separated by filtration and the solid was washed free of acid with water and dried at $383 \mathrm{~K}$ for 3 hours. The solid was ground and sieved to -80 mesh particle size and labeled as $\mathrm{AC}-\mathrm{H}_{2} \mathrm{SO}_{4}$.

The second sulphurization treatment was carried out using carbon disulphide as source of sulphur. $50 \mathrm{~g}$ of AC were soaked in $250 \mathrm{~mL}$ of carbon disulphide, at room temperature, and maintained under stirring for 24 hours. The sulphurized solid was filtered and dried in oven at $383 \mathrm{~K}$ for 3 hours, then was ground and sieved to -80 mesh particle size and labeled as AC-CS .

\subsection{Characterization of adsorbents}

\subsubsection{Proximate and elemental analysis}

The three adsorbents were characterized by proximate analysis, according to ASTM standards. All samples were previously dried in oven at $378 \mathrm{~K}$ until constant weight except for EW, that was analyzed as received. The elemental analysis was performed in a Carlo Erba EA 1108 CHNS-O equipment. The results are expressed on dry and ash free basis.

\subsubsection{Textural properties}

The specific surface and pore size distribution of $\mathrm{AC}, \mathrm{AC}_{-} \mathrm{H}_{2} \mathrm{SO}_{4}$ and $\mathrm{AC}-\mathrm{CS}_{2}$ were determined from the nitrogen adsorption isotherms at $77 \mathrm{~K}$, carried out in a Quantachrome Nova 2200 sorptometer. The adsorption results were modelled by BET in order to determine specific surface, by DR to evaluate micropore volume and by $\mathrm{BJH}$ for pore size distribution.

\subsubsection{Surface chemistry}

\subsubsection{Acid and basic groups}

Surface acid groups were determined by contacting $0.2 \mathrm{~g}$ of the solid with $20 \mathrm{~mL}$ of $0.1 \mathrm{M} \mathrm{NaOH}$ solution. The excess of $\mathrm{NaOH}$ was measured by titration with $0.1 \mathrm{M} \mathrm{HCl}$ solution.

Surface basic groups were determined by contacting $0.2 \mathrm{~g}$ of the solid with $20 \mathrm{~mL}$ of $0.1 \mathrm{M} \mathrm{HCl}$ solution and the excess of $\mathrm{HCl}$, by titration with $0.1 \mathrm{M} \mathrm{NaOH}$ solution.

\subsubsection{Point of zero charge}

The $\mathrm{pH}$ of the point of zero charge, i.e. the $\mathrm{pH}$ above which the total surface of the carbon particles is negatively charged, was measured by the so-called mass titration method proposed by Noh and Schwartz ${ }^{38}$.

\subsection{Batch adsorption studies}

A solution of $40 \mathrm{mg} . \mathrm{L}^{-1}$ of $\mathrm{Hg}$ (II) was prepared by dissolving $0.0541 \mathrm{~g}$ of $\mathrm{HgCl}_{2}$ in $1 \mathrm{~L}$ of distilled water. Batch adsorption tests, which consisted of mixing $50 \mathrm{ml}$ of $\mathrm{Hg}$ (II) solution with different amounts of the adsorbent $(10,20,30,40,50,60,80$ and $100 \mathrm{mg})$ at an initial $\mathrm{pH}=7$, were carried out in $100 \mathrm{~mL}$ conical flasks under stirring until the equilibrium time is reached. The liquid phase was separated from the solid by centrifugation. The adsorption tests were performed at 298 and $318 \mathrm{~K}$, in order to study the temperature influence and at $\mathrm{pH}=3, \mathrm{pH}=7$ and $\mathrm{pH}=10$ to study the $\mathrm{pH}$ influence. The concentration of mercury remnant in the solution was determined by spectrophotometry UV-VIS in a Hach 2010 model equipment. The liquid sample containing the non-adsorbed mercury was complexed with potasium iodine and rhodamine, according to the protocol detailed by Muralidhara ${ }^{39}$ and Kardivelu ${ }^{17}$. The concentration of mercury in solution was determined measuring the absorbance at $575 \mathrm{~nm}$.

\section{Results and Discussion}

\subsection{Proximate and elemental analysis}

The results of the proximate and elemental analysis corresponding to samples EW, CEW, AC, $\mathrm{AC}-\mathrm{H}_{2} \mathrm{SO}_{4}$ and $\mathrm{AC}-\mathrm{CS}_{2}$, are shown in Table 1.

Eucalyptus wood is characterized by a high volatile matter content (VM), low carbon (FC) and ash contents. After the pyrolysis and activation steps, CEW and AC solids present a lower content of

Table 1. Proximate and elemental analysis (expressed in a dry basis).

\begin{tabular}{|c|c|c|c|c|c|c|c|c|c|}
\hline \multirow[t]{2}{*}{ Adsorbent } & \multicolumn{4}{|c|}{ Proximate analysis (wt. (\%)) } & \multicolumn{5}{|c|}{ Ultimate Anlysis (wt. (\%)) } \\
\hline & Hum & VM & $\mathrm{FC}$ & Ash & $\mathrm{C}^{\mathrm{b}}$ & $\mathrm{H}^{\mathrm{b}}$ & $\mathrm{N}^{\mathrm{b}}$ & $\mathrm{O}^{\mathrm{b}}$ & $\mathrm{S}^{\mathrm{b}}$ \\
\hline EW & 10.51 & 69.14 & 19.35 & 1.00 & 45.34 & 6.77 & 0.20 & 47.69 & 0.0 \\
\hline $\mathrm{CEW}^{\mathrm{a}}$ & - & 27.60 & 69.30 & 3.10 & 80.44 & 7.54 & 0.10 & 11.92 & 0.0 \\
\hline $\mathrm{AC}^{\mathrm{a}}$ & - & 7.55 & 89.40 & 3.05 & 88.90 & 1.62 & 0.05 & 9.43 & 0.0 \\
\hline $\mathrm{AC}-\mathrm{H}_{2} \mathrm{SO}_{4}^{\mathrm{a}}$ & - & 8.08 & 88.70 & 3.22 & 82.31 & 1.85 & 0.10 & 12.84 & 2.9 \\
\hline $\mathrm{AC}-\mathrm{CS}_{2}{ }^{\mathrm{a}}$ & - & 7.77 & 89.05 & 3.18 & 88.20 & 1.70 & 0.05 & 5.95 & 4.1 \\
\hline
\end{tabular}

a Dry basis; ${ }^{b}$ Dry and ash free basis. 
Table 2. Textural parameters of the adsorbents.

\begin{tabular}{lcccc}
\hline Adsorbent & $\begin{array}{c}\text { Specific } \\
\text { area } \\
\left(\mathrm{m}^{2} \cdot \mathrm{g}^{-1}\right)\end{array}$ & $\begin{array}{c}\text { Pore } \\
\text { volume } \\
\left(\mathrm{cm}^{3} \cdot \mathrm{g}^{-1}\right)\end{array}$ & $\begin{array}{c}\text { Micropore } \\
\text { volume } \\
\left(\mathrm{cm}^{3} \cdot \mathrm{g}^{-1}\right)\end{array}$ & $\begin{array}{c}\text { Mesopore } \\
\text { volume } \\
\left(\mathrm{cm}^{3} \cdot \mathrm{g}^{-1}\right)\end{array}$ \\
\hline $\mathrm{AC}$ & 701 & 0.51 & 0.26 & 0.25 \\
$\mathrm{AC}-\mathrm{H}_{2} \mathrm{SO}_{4}$ & 979 & 0.72 & 0.35 & 0.37 \\
$\mathrm{AC}-\mathrm{CS}_{2}$ & 582 & 0.42 & 0.21 & 0.21 \\
\hline
\end{tabular}

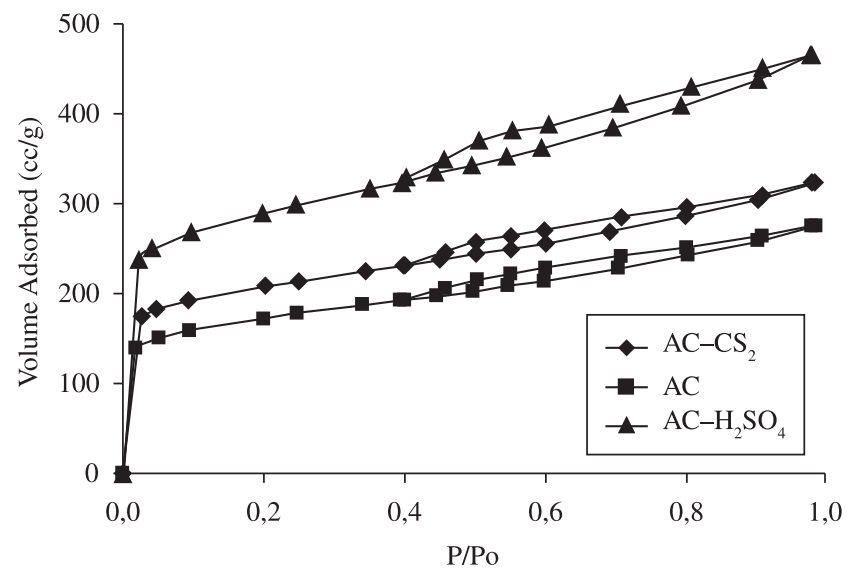

Figure 1. Adsorption-desorption isotherms for nitrogen at $77 \mathrm{~K}$.

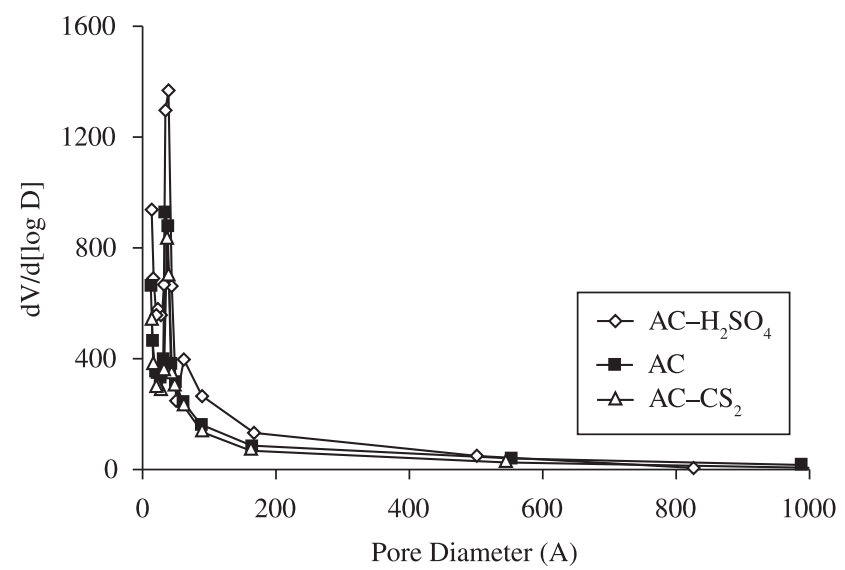

Figure 2. Pore size distribution of the adsorbents.

volatile matter and a higher carbon and ash content, compared with that of EW.

The higher content of volatile matter and sulphur of the $\mathrm{AC}-\mathrm{H}_{2} \mathrm{SO}_{4}$ and $\mathrm{AC}-\mathrm{CS}_{2}$ adsorbents compared with that of the AC solid indicates the effective incorporation of sulphur onto the adsorbent surface.

By comparing the sulphur content of samples $\mathrm{AC}-\mathrm{CS}_{2}$ and $\mathrm{AC}-\mathrm{H}_{2} \mathrm{SO}_{4}$, it can be concluded that the impregnation treatment with $\mathrm{CS}_{2}$ was more efficient than that with $\mathrm{H}_{2} \mathrm{SO}_{4}$.

\subsection{Textural characterization of the adsorbents}

Figures 1 and 2 show the adsorption isotherms and the pore size distributions corresponding to the three studied adsorbents. Table 2 summarizes the main textural parameters of the adsorbents.

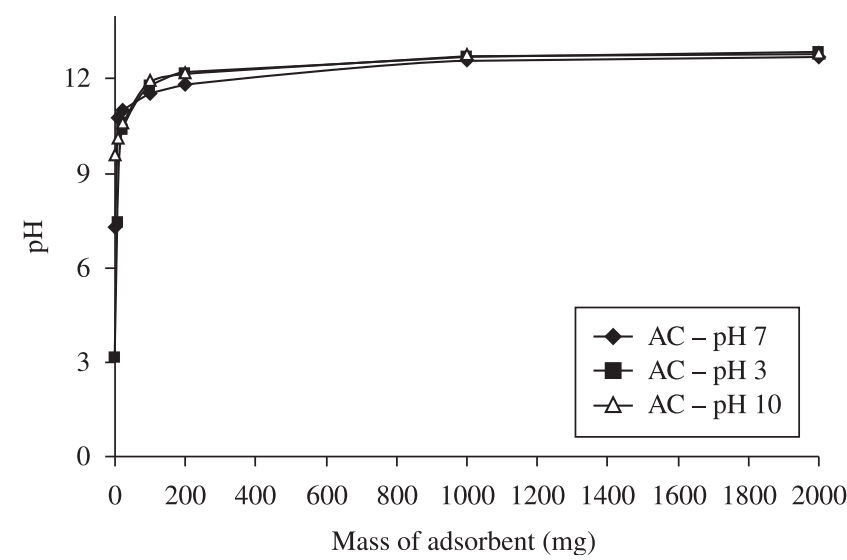

Figure 3. Point of zero charge of $\mathrm{AC}$ adsorbent by mass titration.

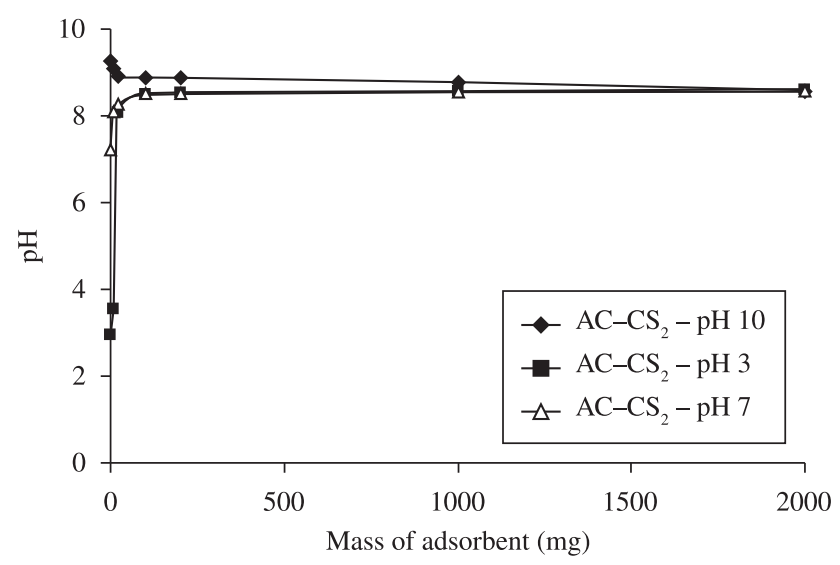

Figure 4. Point of zero charge of AC-CS, adsorbent by mass titration.

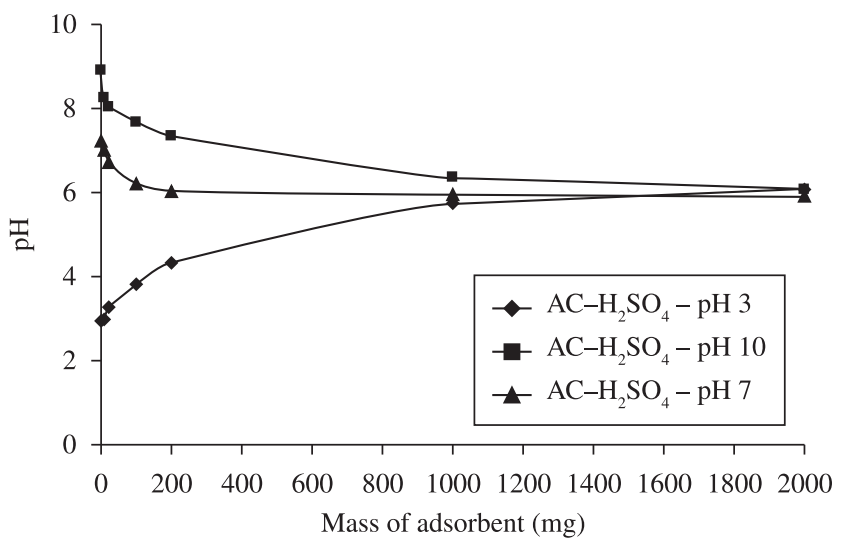

Figure 5. Point of zero charge of $\mathrm{AC}-\mathrm{H}_{2} \mathrm{SO}_{4}$ adsorbent by mass titration.

The adsorption isotherms corresponding to $\mathrm{AC}-\mathrm{H}_{2} \mathrm{SO}_{4}$ and $\mathrm{AC}-\mathrm{CS}_{2}$ show important variations compared with that of AC, mainly in the position of the knee of the isotherm, which basically indicates that the microporous structure has been substantially modified by the sulphurization treatments. The increase of the micropore volume in the $\mathrm{AC}-\mathrm{H}_{2} \mathrm{SO}_{4}$ adsorbent could be the result of a chemical activation caused by the sulphuric acid which generates more cavities. 
The decrease of the micropore volume observed for the AC-CS 2 sample could be associated to a pore blocking effect due to the surface sulphurized groups. Increment in the mesoporous volume corresponding to the $\mathrm{AC}-\mathrm{H}_{2} \mathrm{SO}_{4}$ adsorbent is also produced. However, from the hysteresis loop shape, the mean connectivity of the porous net does not vary after the sulphurization treatments ${ }^{40-42}$.

From the textural properties, the adsorption capacity of a solid depends on the specific surface area, the pore size distribution and the mean connectivity of the porous net. Because of its higher specific surface and pore volume $\mathrm{AC}-\mathrm{H}_{2} \mathrm{SO}_{4}$ should be better adsorbent than $\mathrm{AC}$ and $\mathrm{AC}-\mathrm{CS}_{2}$. Furthermore, from the surface chemistry point of view, AC- $\mathrm{H}_{2} \mathrm{SO}_{4}$ is better adsorbent than $\mathrm{AC}$ because the surface sulphurized groups are specially favourable for mercury adsorption ${ }^{30-35}$.

A lower mercury adsorption capacity should be observed for the AC-CS 2 adsorbent due to the important decreasing of specific surface and pore volume compared to the AC adsorbent. However

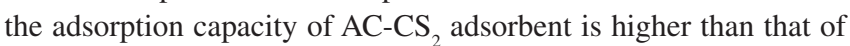
$\mathrm{AC}$, because its unfavourable textural properties are balanced by the surface chemistry which improves the mercury adsorption.

\subsection{Surface chemistry}

Figures 3, 4 and 5 show the results of the mass titration carried out in order to obtain the $\mathrm{pH}$ corresponding to the point of zero charge

Table 3. Acid and basic surface groups and $\mathrm{pH}_{\mathrm{PZC}}$ experimental results.

\begin{tabular}{lcccc}
\hline Adsorbent & $\begin{array}{c}\text { Acid groups } \\
\left(\mathrm{mEq} . \mathrm{g}^{-1}\right)\end{array}$ & $\begin{array}{c}\text { Basic groups } \\
\left(\mathrm{mEq} . \mathrm{g}^{-1}\right)\end{array}$ & $\begin{array}{c}\text { Acid/Basic } \\
\text { ratio }\end{array}$ & $\mathrm{pH}_{\mathrm{PZO}}$ \\
\hline $\mathrm{AC}$ & 1.08 & 4.52 & 0.24 & 13.1 \\
$\mathrm{AC}-\mathrm{H}_{2} \mathrm{SO}_{4}$ & 1.46 & 4.94 & 0.30 & 6.1 \\
$\mathrm{AC}^{-\mathrm{CS}_{2}}$ & 1.06 & 2.31 & 0.46 & 8.5 \\
\hline
\end{tabular}

Table 4. Parameters of the Freundlich equation.

\begin{tabular}{lccc}
\hline Adsorbent & $\log \mathrm{k}$ & $1 / \mathrm{n}$ & $\mathrm{R}^{2}$ \\
\hline $\mathrm{AC}$ & 0.92 & 1.09 & 0.976 \\
$\mathrm{AC}-\mathrm{H}_{2} \mathrm{SO}_{4}$ & 1.65 & 0.88 & 0.981 \\
$\mathrm{AC}-\mathrm{CS}_{2}$ & 0.55 & 1.57 & 0.980 \\
\hline
\end{tabular}

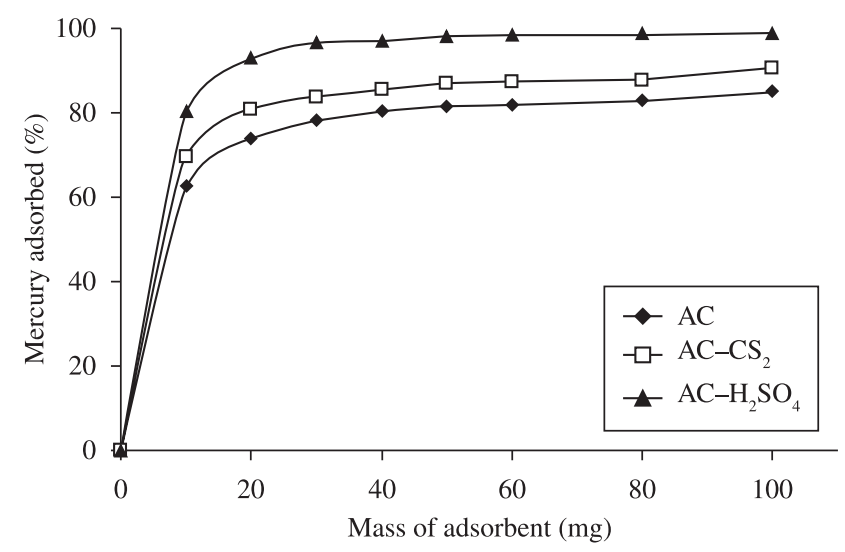

Figure 6. Adsorption isotherms of mercury. for the studied adsorbents. Table 3 summarizes the results of the acid and basic surface groups and $\mathrm{pH}_{\mathrm{PZC}}$ of the studied adsorbents.

The analysis of the acid and basic surface groups indicates that the sulphurization treatment with $\mathrm{H}_{2} \mathrm{SO}_{4}$ has increased the number of both types of sites, compared with that of the AC adsorbent, due to the changes in the textural properties of the modified solid and the changes in the surface chemistry. The (acid groups: basic groups) ratio shows variations in the surface chemistry due to this sulphurization treatment.

More important changes in the number and type of surface groups have been observed in the AC-CS 2 adsorbent, compared to those corresponding to the $\mathrm{AC}$ adsorbent, due not only to the structural changes in the sulphurized adsorbent but also to the surface chemical changes, basically measured by the number of acid and basic groups per gram of the adsorbent and by the (acid groups: basic groups) ratio, substantially different to that of the untreated adsorbent.

The $\mathrm{pH}_{\mathrm{PZO}}$ values corresponding to the sulphurized adsorbents are considerably different to that of the untreated solid which predicts different behaviour of the three solids with the $\mathrm{pH}$ of the solution.

\subsection{Batch adsorption studies}

Figure 6 shows the percentage of mercury adsorbed with respect to the original content in the solution, after the batch adsorption test at $298 \mathrm{~K}$ and $\mathrm{pH}=7$. The highest adsorption of mercury corresponds to the $\mathrm{AC}-\mathrm{H}_{2} \mathrm{SO}_{4}$ adsorbent and the lowest one to the $\mathrm{AC}$ solid. The experimental datapoints were modelled by the Freundlich equation and the results of the linear regression are summarized in Table 4.

The analysis of the Freundlich model parameters for the adsorption data at a fixed $\mathrm{pH}$ and temperature shows that the highest adsorption capacity corresponds to the $\mathrm{AC}-\mathrm{H}_{2} \mathrm{SO}_{4}$ adsorbent (highest value of the $\mathrm{k}$ Freundlich parameter), which is due mainly to the varitations in the textural properties of the solid provoked by the sulphuric acid. This sulphurization treatment produced slight changes in the surface chemistry in comparison with the AC adsorbent (similar values of the $1 / \mathrm{n}$ Freundlich parameter).

More important changes in the surface chemistry were produced when carbon disulphide was used as sulphurizing agent (different $1 / n$ Freundlich parameter compared to those corresponding to $\mathrm{AC}$ and $\mathrm{AC}-\mathrm{H}_{2} \mathrm{SO}_{4}$ adsorbents). This modification balanced the unfavorable change in the textural properties so the observed mercury adsorption capacity of the modified solid was higher than that of the untreated adsorbent. These results are in agreement with those corresponding to the surface acid and basic groups.

\subsubsection{Temperature influence}

The temperature of the adsorption tests does not influence the adsorption capacity of the studied adsorbents. As an example, Figure 7 corresponding to the $\mathrm{AC}-\mathrm{H}_{2} \mathrm{SO}_{4}$ adsorbent, is included. Similar behavior is observed for the other tested adsorbents. This is because, although the adsorption process is exothermic in nature, the condensation of a solute onto the adsorbent surface only occurs by the displacement of a solvent molecule previously adsorbed (endothermic process). If the heat of adsorption of a solute molecule is similar to that of the desorption of the solvent molecule, the whole process will not be influenced by the temperature.

\subsection{2. $\mathrm{pH}$ influence}

The effectiveness with which a solute is entraped by an adsorbent is influenced by the $\mathrm{pH}$ of the solution. The speciation also depends on the $\mathrm{pH}$ of the solution ${ }^{24}$. The adsorption of mercury by the studied adsorbents could be enhanced when the net surface charge and the 


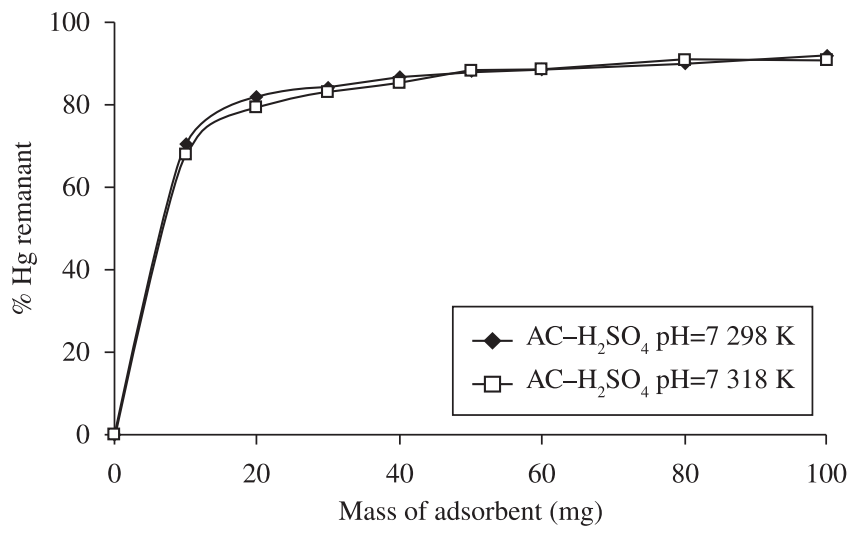

Figure 7. Effect of temperature on removal of $\mathrm{Hg}(\mathrm{II})$ for $\mathrm{AC}-\mathrm{H}_{2} \mathrm{SO}_{4}$.

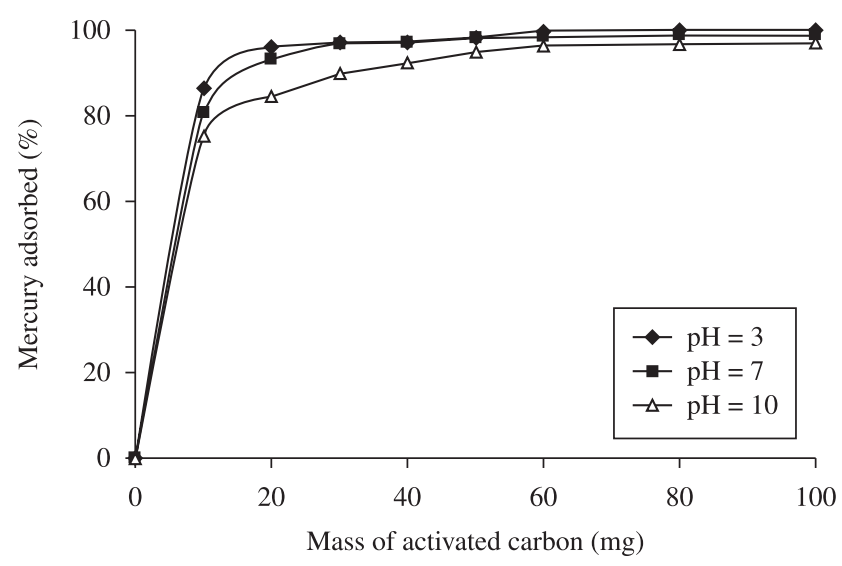

Figure 8. Effect of $\mathrm{pH}$ on removal of $\mathrm{Hg}(\mathrm{II})$ for $\mathrm{AC}-\mathrm{H}_{2} \mathrm{SO}_{4}$.

charge that of the specie which contains the metal in the solution are different. Simultaneous studies of speciation and point of zero charge will allow to determine the $\mathrm{pH}$ of the solution for a maximun adsorption.

Figure 8 shows that the $\mathrm{AC}-\mathrm{H}_{2} \mathrm{SO}_{4}$ adsorbent presents higher adsorption capacity at $\mathrm{pH}=3$ compared to $\mathrm{pH}=7$ and $\mathrm{pH}=10$. This behavior can be explained through the analysis of the net surface charge of the adsorbent and the charge of the species in which mercury is in solution. For example, $\mathrm{pH}_{\mathrm{PZC}}=6$ for the $\mathrm{AC}-\mathrm{H}_{2} \mathrm{SO}_{4}$ adsorbent. When the adsorption test is carried out at $\mathrm{pH}=3$, the net charge of the solid surface is positive. At $\mathrm{pCl}=3.8$ and $\mathrm{pH}=3$ the dominant species in solution are $\left(\mathrm{HgCl}_{2}\right)\left(\mathrm{HgCl}_{3}\right)^{-}$. Then the electrostatic attraction forces between the solid surface and the negative charged species will enhace the adsorption. When the adsorption test is carried out at $\mathrm{pH}=7$ (closed to the $\mathrm{pH}_{\mathrm{PZC}}$ of the adsorbent) the net charge of the surface is closed to zero. In this case, no matter the speciation, there is not an important electrostatic effect compared to that at $\mathrm{pH}=3$ and the adsorbent capacity of the solid dimishes compared to that at $\mathrm{pH}=3$. For the adsorption test at $\mathrm{pH}=10$, the net charge of the solid surface is negative and the main species in solution are $\left(\mathrm{HgCl}_{2}\right)\left(\mathrm{HgCl}_{3}\right)^{-}$. In this case there is a repulsion electrostatic effect between the solid surface and the negative charged species. Then, the adsorption of the mercury species is more difficult compared to that observed at $\mathrm{pH}=3$ and $\mathrm{pH}=7$. A similar analysis of the $\mathrm{AC}$ and $\mathrm{AC}-\mathrm{CS}_{2}$ adsorbents can explain the adsorption capacities observed at different solution $\mathrm{pH}$.

\section{Conclusions}

The activated carbon from carbonized eucalyptus wood is an adequate adsorbent for mercury entrapment from aqueous solutions and its adsorbent efficiency can be enhanced by the modification of its surface chemistry. The improvement in the adsorbent capacity depends not only on the surface modifications, but also on the charge of the solute in the solution. Both factors depend on the $\mathrm{pH}$ of the solution.

The surface sulphurization treatments produce important variations in the zero charge point, in the textural properties of the solid (basically specific surface and pore size distribution) and in the number of acid and basic surface groups.

From the analysis of the above mentioned factors, the dependency of the adsorption capacity of a solid with the $\mathrm{pH}$ of the solution can be explained. The temperature does not influence significantly the adsorption properties of the solid studied. A slight increment of the adsorption capacity with temperature is observed. This behavior is due to the energetic changes which occur when a solute molecule replaces a solvent molecule onto the solid surface.

From the adsorption data, modelled by the Freundlich equation, it can be concluded that the surface treatment with sulphuric acid produces important changes on the porous structure of the adsorbent and on the surface chemistry which explains its highest adsorption capacity. The sulphurization treatment with carbon disulphide also produces important changes in both, textural properties and surface chemistry of the solid. In this case, the decrease in the surface area and pore volume is balanced by a favourable surface chemistry for mercury adsorption which makes this adsorbent better than the untreated solid (AC).

This information will be useful in order to predict the behaviour of the adsorbents in dynamic adsorption studies which in turn will allow to determine, after the scale up, the size of the industrial adsorption units.

\section{Acknowledgements}

The Financial support of this work by Universidad Nacional de San Juan, Argentina, is gratefully acknowledged.

\section{References}

1. Patterson J. Capsule Report: Aqueous Mercury Treatment. Cincinnati, OH: National Risk Management Research Laboratory, Office of Research and Development, United States Environmental Protection; 1997

2. Kadirvelu K, Thamaraiselvi K and Namasivayam C. Removal of heavy metals from industrial wastewaters by adsorption onto activated carbon prepared from an agricultural solid waste. Bioresource Technology. 2001; 76(1):63-65.

3. Babic B, Milonjic S, Polovina M, Cupic S and Kaludjerovic B. Adsorption of zinc, cadmium and mercury ions from aqueous solutions on an activated carbon cloth. Carbon. 2002; 40(7):1109-1115.

4. Velicu M, Fua H, Suri RPS and Woods K. Use of adsorption process to remove organic mercury thimerosal from industrial process wastewater. Journal of Hazardous Materials. 2007; 148(3):599-605.

5. Inbaraj S and Sulochana N. Mercury adsorption on a carbon sorbent derived from fruit shell of Terminalia catappa B. Journal of Hazardous Materials B. 2006; 133(1-3): 283-290.

6. Antochshuk V, Olkhovyk O, Jaroniec M, Park I and Ryoo R. Benzoylthiourea-modified mesoporous silica for mercury (II) removal. Langmuir. 2003; 19(7):3031-3034.

7. Costa L, Araujo M, Sapag K, Sardella M, Silva H, Deiana C and Lago RM. High surface area functionalized carbon briquettes: A novel adsorbent for metals from water. Journal of the Brazilian Chemical Society. 2005; 16(5):899-902. 
8. Namasivayam C and Kadirvelu K. Uptake of mercury(II) from wastewater by activated carbon from an unwanted agricultural waste by-product: coirpith. Carbon. 1999; 37(1):79-84.

9. Baçaoui A, Yaacoubi A, Dahbi A, Bennouna C, Phan Tan Luu R, Maldonado-Hodarc FJ, Rivera-Utrillac J and Moreno-Castilla C. Optimization of conditions for the preparation of activated carbons from olive-waste cakes. Carbon. 2001; 39(3):425-432.

10. Amaya A, Medero N, Tancredi N, Silva H and Deiana C. Activated carbon briquettes from biomass materials. Bioresource Technology. 2007 ; 98(8):1635-1641.

11. Deiana C, Granados D, Petkovic L, Sardella M and Silva H. Use of grape must as a binder to obtain activated carbon briquettes. Brazilian Journal of Chemical Engineering. 2004; 21(4):585-591.

12. Budinova T, Petrova N, Parrab J and Baloutzov V. Use of an activated carbon from antibiotic waste for the removal of $\mathrm{Hg}$ (II) from aqueous solution. Journal of Environmental Management. 2008; 88(1):165-172.

13. Namasivayam C and Sangeetha D. Recycling of agricultural solid waste, coir pith: Removal of anions, heavy metals, organics and dyes from water by adsorption onto $\mathrm{ZnCl}_{2}$ activated coir pith carbon. Journal of Hazardous Materials. 2006; 135(1-3):449-452.

14. Goel J, Kadirvelu K, Rajagopal C and Garg V. Removal of mercury (II) from aqueous solution by adsorption on carbon aerogel: Response surface methodological approach. Carbon. 2005; 43(1):197-200.

15. Mullett M, Tardio J, Bhargava S and Dobbsc C. Removal of mercury from an alumina refinery aqueous stream. Journal of Hazardous Materials. 2007; 144(1-2):274-282.

16. Zenga H, Jin F and Guo J. Removal of elemental mercury from coal combustion flue gas by chloride-impregnated activated carbon. Fuel. 2004; 83(1):143-146.

17. Kadirvelu K, Kavipriya M, Karthika C, Vennilamani N and Pattabhi S. Mercury (II) adsorption by activated carbon made from sago waste. Carbon. 2004; 42(4):745-752.

18. Yardim M, Budinova T, Ekinci E, Petrov N, Razvigorova M and Minkova V. Removal of mercury (II) from aqueous solution by activated carbon obtained from furfural. Chemosphere. 2003; 52(5):835-841.

19. Ranganathan $\mathrm{K}$. Adsorption of $\mathrm{Hg}(\mathrm{II})$ ions from aqueous chloride solutions using powdered activated carbons. Carbon. 2003; 41(5):1087-1092.

20. Lee $S$ and Park Y. Gas-phase mercury removal by carbon-based sorbents. Fuel Processing Technology. 2003; 84(1):197-206.

21. Ekinci E, Budinova T, Yardim F, Petrov N, Razvigorova M and Minkova V. Removal of mercury ion from aqueous solution by activated carbons obtained from biomass and coals. Fuel Processing Technology. 2002; 77-78(1): 437-443.

22. Gregg S and Sing K. Adsorption, Surface Area and Porosity. 2 ed. London: Academic Press; 1982.

23. Maroto-Valera M, Zhanga Y, Graniteb E, Tanga Z and Pennlineb H. Effect of porous structure and surface functionality on the mercury capacity of a fly ash carbon and its activated sample. Fuel. 2005; 84(1):105-108.

24. Carrott P, Ribeiro Carrott $M$ and Nabais J. Influence of surface ionization on the adsorption of aqueous mercury chlorocomplexes by activated carbons. Carbon. 1998; 36(1-2):1-17.

25. Pastor-Villegas J, Meneses Rodrí́guez JM, Pastor-Valle JF and García García M. Changes in commercial wood charcoals by thermal treatments. Journal of Analytical and Applied Pyrolisis. 2007; 80(2):507-514.
26. Domingo-García M, López-Garzón F and Pérez-Mendoza M. Effect of some oxidation treatments on the textural characteristics and surface chemical nature of an activated carbon. Journal of Colloid and Interface Science. 2000; 222(2):233-240.

27. Rios R, Alves D, Dalmázio I, Bento S, Donnici C and Lago R. Tailoring activated carbon by surface chemical modification with $\mathrm{O}, \mathrm{S}$, and $\mathrm{N}$ containing molecules. Materials Research. 2003; 6(2):129-135.

28. Perez-Cadenas A, Maldonado-Hodar F and Moreno-Castilla C. On the nature of surface acid sites of chlorinated activated carbons. Carbon. 2003; 41(3):473-478.

29. Li Y. Importance of activated carbon's oxygen surface functional groups on elemental mercury adsorption. Fuel. 2003; 82(4): 451-457.

30. Anoop K and Anirudhan T. Removal of mercury (II) from aqueous solutions and chlor-alkali industry effluent by steam activated and sulphurised activated carbons prepared from bagasse pith: kinetics and equilibrium studies. Journal of Hazardous Materials B. 2002; 92(2):161-183.

31. Manchón-Vizuete E, Macías-García A, Nadal Gisbert A, FernándezGonzález C and Gómez-Serrano V. Adsorption of mercury by carbonaceous adsorbents prepared from rubber of tyre wastes. Journal of Hazardous Materials B. 2005; 119(1-3):231-238.

32. Hsi H, Rood M, Rostam-Abadi M, Chen S and Chang R. Adsorption properties of sulfur-impregnated adsorbents. Journal of Environmental Engineering. 2002; 128(11):1080-1089.

33. Gómez Serrano V, Macías García A, Espinosa Mansilla A and Valenzuela Calahorro C. Adsorption of mercury, cadmiun and lead from aqueous solution on heat-treated and sulphurized activated carbon. Water Research. 1998; 32(1):1-4.

34. Vitolo $\mathrm{S}$ and Pini R. Deposition of sulfur from $\mathrm{H}_{2} \mathrm{~S}$ on porous adsorbents and effect on their mercury adsorption capacity. Geothermics. 1999; 28(3):341-354.

35. O'Dowd W, Hargis R, Granite E and Pennline H. Recent advances in mercury removal technology at the National Energy Technology Laboratory. Fuel Processing Technology. 2004; 85(6-7):533-548.

36. Deiana C, Petkovic L and Noriega S. Carbón activado a partir de materias primas regionales. Información Tecnológica. 1998; 9(5):89-93.

37. Deiana AC, Granados DL, Petkovic LM, Sardella MF and Silva HS. Use of grape must as a binder to obtain activated carbon briquettes. Brazilian Journal of Chemical Engineering. 2004; 21(4):585-591.

38. Noh J and Schwartz J. Estimation of the point of zero charge of simple oxides by mass titration. Journal of Colloid and Interface Science. 1989; 130(1):157-164.

39. Muralidhara B. Indirect complexometric determination of mercury using potassium iodide as selective masking agent. Turkish Journal of Chemistry. 1998; 22(3):215-219.

40. Seaton N. Determination of the connectivity of porous solids from nitrogen sorption measurements. Chemical Engineering Science. 1991; 46(2):1895-1909

41. Liu H and Seaton N. Determination of the connectivity of porous solids from nitrogen sorption measurements-II, generalisation. Chemical Engineering Science. 1992; 47(17/18): 4393-4404.

42. Liu H and Seaton N. Determination of the connectivity of porous solids from nitrogen sorption measurements-III, solids containing large mesoporous. Chemical Engineering Science. 1994; 49(11):1869-1878. 